\title{
Evaluasi Kapasitas Ruas Jalan Pantura Kabupaten Brebes
}

\author{
${ }^{凶}$ Untoro Nugroho ${ }^{1}$, Agung Sutarto $^{1}$, Fenty Endradewi ${ }^{1}$, Yuliana Nur Alisa ${ }^{1}$ \\ ${ }^{1}$ Jurusan Teknik Sipil, Fakultas Teknik, Universitas Negeri Semarang (UNNES)
}

\begin{tabular}{l} 
Kata Kunci/ Keywords : \\
\hline Pantura Road, Ttraffic Jams, The \\
ratio of Volume Capacity \\
Jalan Pantura, Kemacetan Lalu- \\
lintas, Rasio Volume Kapasitas.
\end{tabular}

\begin{abstract}
Abstrak:
Brebes is one of the districts traversed by the road north coast. Congestion on roads pantura frequent because this road is a national road along the coast of the island of Java. Long road pantura Brebes \pm $32.8 \mathrm{Km}$. The purpose of this study was to evaluate the capacity of roads pantura Brebes based on the volume of traffic there and know how big the relationship between the ratio of volume per capacity and traffic jams that occur on the road north coast Brebes. This research was conducted along the northern coast Brebes district. The data used are the characteristics data, inventory data path, the data traffic volume and vehicle speed data. Analysis was conducted on the Analysis of Traffic Volume, capacity analysis segment, analysis of vehicle speed, intersection capacity analysis, the analysis of the degree of saturation, analysis level of service redesign and analysis of road.
\end{abstract}

Brebes merupakan salah satu kabupaten yang dilalui oleh jalan pantura. Kemacetan pada jalan pantura sering terjadi karena jalan ini merupakan jalan nasional di sepanjang pesisir Pulau Jawa. Panjang jalan pantura Kabupaten Brebes $\pm 32,8 \mathrm{Km}$. Adapun tujuan penelitian ini adalah untuk mengevaluasi kapasitas ruas jalan pantura Kabupaten Brebes berdasarkan volume lalu-lintas yang ada dan mengetahui seberapa besar tingkat hubungan antara rasio volume per kapasitas dan kemacetan lalu lintas yang terjadi di jalan pantura Kabupaten Brebes. Penelitian ini dilakukan di sepanjang jalan Pantura Kabupaten Brebes, yang dibagi dalam 16 ruas dan 15 simpang pada 5 kecamatan sepanjang Jalan Pantura. Data yang digunakan adalah data karakteristik jalan, data inventori jalan, data volume lalu lintas dan data kecepatan kendaraan. Analisis yang dilakukan meliputi Analisis Volume Lalu Lintas, analisis kapasitas ruas, analisis kecepatan kendaraan, analisis kapasitas simpang, analisis derajat kejenuhan, analisis tingkat pelayanan jalan dan analisis redesign jalan.

Sitasi:

Nugroho, Untoro, dkk. (2017). Evaluasi Kapasitas Ruas Jalan Pantura Kabupaten Brebes. Jurnal Teknik Sipil \& Perencanaan, 19(1), 71 - 76

\footnotetext{
Untoro Nugroho:
} 


\section{PENDAHULUAN \\ Latar Belakang}

Brebes merupakan salah satu kabupaten yang dilalui oleh jalan pantura. Jalan ini memiliki signifikansi yang sangat tinggi dan menjadi urat nadi utama dalam transportasi darat. Kemacetan pada jalan pantura sering terjadi karena jalan ini merupakan jalan nasional di sepanjang pesisir Pulau Jawa. Panjang jalan pantura Kabupaten Brebes $\pm 32,8 \mathrm{Km}$, membentang melewati 5 (lima) kecamatan yaitu Kecamatan Brebes, Wanasari, Bulakamba, Tanjung dan Losari. Meningkatnya volume Kapasitas Ruas Jalan Pantura Kabupaten Brebes tiap tahunnya menyebabkan derajat kejenuhan meningkat sehingga terjadi kemacetan pada jalan tersebut. Adapun tujuan penelitian ini adalah untuk mengevaluasi kapasitas ruas jalan pantura Kabupaten Brebes, berdasarkan volume lalu-lintas yang ada sehingga mengetahui seberapa besar tingkat hubungan antara rasio volume per kapasitas dan kemacetan lalu lintas yang terjadi. Hal tersebutlah yang akan diteliti sehingga dapat diketahui pemicu dari prmasalahan kemacetan yang terjadi di kota Brebes.

\section{METODE PENELITIAN \\ Lokasi Penelitian dan Analisiis yang Dilaksanakan}

Penelitian ini dilaksanakan di sepanjang ruas jalan Pantura Kabupaten Brebes dengan menitikberatkan pada analisis volume lalu lintas pada titik-titik lokasi yang telah ditentukan. Analisis kapasitas ruas jalan pantura dengan keadaan lapangan yang ada pada tahun 2016. Analisis yang dilaksanakan pada penelitian ini adalah kecepatan kendaraan, kapasitas pada simpang, rasio volume per kapasitas (derajat kejenuhan) dan analisis perencanaan ulang jalan.

\section{Data yang Digunakan}

Data Sekunder :

(1) Data volume lalu-lintas dari Dinas Perhubungan Kabupaten Brebes yang di ambil pada tahun 2014.

(2) Data karakteristik jalan dari Dinas Bina Marga Kabupaten Brebes pada tahun terakhir yang digunakan sebagai pedoman dalam pengambilan data primer karakteristik jalan.

Data Primer :

(1) Data karakteristik jalan melihat kondisi jalan yang ada di lokasi pengamatan.

(2) Volume arus lalu-lintas dengan menghitung banyaknya kendaraan yang lewat pada garis pengamatan yang telah ditentukan selama waktu pengamatan.
(3) Kapasitas ruas jalan dan simpang dengan cara menganalisa sesuai dengan kondisi jalan dengan melihat tata guna lahan.

(4) Data Kecepatan Kendaraan. Data ini diambil secara langsung dilapangan. Data yang di ambil yaitu kecepatan kendaraan yang melintas pada waktu tertentu dalam $\mathrm{km} / \mathrm{jam}$.

(5) Data Inventori Jalan. Data ini diambil secara langsung di lapangan. Data yang diambil antara lain data-data kelengkapan jalan, alinyemen, median jalan, dll.

\section{HASIL DAN PEMBAHASAN \\ Daerah Penelitian}

Jalan Pantura di Pulau Jawa mempunyai panjang $1.316 \mathrm{~km}$ membentang dari Merak sampai Ketapang. Brebes merupakan salah satu kabupaten yang dilalui oleh jalan pantura. Jalan Pantura di Kabupaten Brebes dari arah Jakarta mulai dari Losari sampai Kaligangsa. Melewati 5 kecamatan yaitu Kecamatan Brebes, Wanasari, Bulakamba, Tanjung dan Losari. Identifiaksi dari perbatasan pantura Brebes antara lain arah barat adalah gapura perbatasan Jawa Tengah-Jawa Barat, Kecamatan Losari. Arah Timur adalah gapura perbatasan Kabupaten Brebes-Kabupaten Tegal, Desa Kaligangsa.

\section{Data Volume Ruas Lalu Lintas Jalan Pantura Kabupaten Brebes}

Volume lalu lintas pada jam puncak dihitung kembali secara langsung di lapangan untuk mendapatkan volume kepadatan jam puncak yang lebih valid. Metode pengambilan data pada ruas pantura Kabupaten Brebes dilaksanakan pada 5 jam pada jam puncak pagi dan 3 jam pada jam puncak sore. Pada jam puncak pagi dilaksanakan pada jam 08.00 - 13.00 WIB sedangkan pada jam puncak sore dilaksanakan pada jam 15.30 18.30 WIB. Berikut ini adalah data rekap volume yang diambil pada 4 ruas Jalan Pantura Kabupaten Brebes.

Tabel 1. Data Volume Kendaraan Tertinggi pada Jam Puncak Pagi

\begin{tabular}{lccc}
\hline $\begin{array}{l}\text { Ruas Jalan } \\
\text { Pantura } \\
\text { Kecamatan }\end{array}$ & \multicolumn{2}{c}{$\begin{array}{c}\text { Volume Lalu Lintas } \\
\text { (smp/jam) }\end{array}$} & $\begin{array}{c}\text { Total 2 } \\
\text { Arah }\end{array}$ \\
\cline { 2 - 3 } & $\begin{array}{c}\text { Arah } \\
\text { Semarang }\end{array}$ & $\begin{array}{c}\text { Arah } \\
\text { Jakarta }\end{array}$ & \\
\hline Brebes & 2202 & 2342 & 4504 \\
\hline Wanasari & 2319 & 2805 & 5034 \\
\hline Bulakamba & 2059 & 2331 & 4364 \\
\hline Losari & 1234 & 1509 & 2743 \\
\hline
\end{tabular}


Tabel 2. Data Volume Kendaraan Tertinggi pada Jam Puncak Sore

\begin{tabular}{lccc}
$\begin{array}{l}\text { Ruas Jalan } \\
\begin{array}{l}\text { Pantura } \\
\text { Kecamatan }\end{array}\end{array}$ & \multicolumn{2}{c}{$\begin{array}{c}\text { Volume Lalu Lintas } \\
\text { (smp/jam) }\end{array}$} & $\begin{array}{c}\text { Total 2 } \\
\text { Arah }\end{array}$ \\
\cline { 2 - 3 } & $\begin{array}{c}\text { Arah } \\
\text { Semarang }\end{array}$ & $\begin{array}{c}\text { Arah } \\
\text { Jakarta }\end{array}$ & \\
\hline Brebes & 1979 & 2127 & 4106 \\
\hline Wanasari & 2232 & 2654 & 4886 \\
\hline Bulakamba & 1900 & 2102 & 4002 \\
\hline Losari & 1252 & 1407 & 2646 \\
\hline
\end{tabular}

\section{Data Kecepatan Kendaraan}

Data kecepatan kendaraan yang melintas diambil dengan menggunakan alat speed gun pada masing-masing ruas yang ditentukan yaitu ruas Kecamatan Brebes, ruas Kecamatan Wanasari, ruas Kecamatan Bulakamba dan ruas Kecamatan Losari. Data tersebut akan digunakan sebagai salah satu nilai faktor pada penentuan tingkat pelayanan jalan sesuai dengan Peraturan Menteri Perhubungan yang ada. Berikut ini merupakan tabel hasil data kecepatan kendaraan pada ruas Jalan Pantura Kabupaten Brebes di masing-masing kecamatan.

Tabel 3. Data Kecepatan Kendaraan Tertinggi pada Jam Puncak Pagi

\begin{tabular}{|c|c|c|c|}
\hline \multirow{2}{*}{$\begin{array}{l}\text { Ruas Jalan } \\
\text { Pantura } \\
\text { Kecamatan }\end{array}$} & \multicolumn{3}{|c|}{$\begin{array}{l}\text { Kecepatan Kendaraan Maksimal } \\
\text { (km/jam }\end{array}$} \\
\hline & $\begin{array}{c}\text { Arah } \\
\text { Semarang }\end{array}$ & $\begin{array}{c}\text { Arah } \\
\text { Jakarta }\end{array}$ & $\begin{array}{l}\text { Kedua } \\
\text { Arah }\end{array}$ \\
\hline Brebes & 38.83 & 38.56 & 38.70 \\
\hline Wanasari & 45.11 & 43.12 & 43.87 \\
\hline Bulakamba & 55.78 & 56.05 & 54.87 \\
\hline Losari & 61.73 & 54.38 & 58.06 \\
\hline
\end{tabular}

Tabel 4. Data Kecepatan Kendaraan Tertinggi pada Jam Puncak Sore

\begin{tabular}{lccc}
\hline $\begin{array}{l}\text { Ruas Jalan } \\
\text { Pantura } \\
\text { Kecamatan }\end{array}$ & \multicolumn{3}{c}{$\begin{array}{c}\text { Kecepatan Kendaraan Maksimal } \\
(\mathrm{km} / \mathrm{jam})\end{array}$} \\
\cline { 2 - 4 } & $\begin{array}{c}\text { Arah } \\
\text { Semarang }\end{array}$ & $\begin{array}{c}\text { Arah } \\
\text { Jakarta }\end{array}$ & $\begin{array}{c}\text { Kedua } \\
\text { Arah }\end{array}$ \\
\hline Brebes & 42.53 & 42.10 & 42.26 \\
\hline Wanasari & 46.23 & 46.50 & 46.26 \\
\hline Bulakamba & 57.39 & 57.28 & 56.88 \\
\hline Losari & 65.11 & 57.92 & 61.38 \\
\hline
\end{tabular}

Data Volume Simpang Lalu Lintas Jalan Pantura Kabupaten Brebes

Data penelitian yang diambil yaitu data pada titik simpang yang berada di masingmasing kecamatan yang memiliki tingkat faktor penyebab permasalahan lalu lintas paling besar. Pada kecamatan Brebes diambil data penelitian di Simpang Pasar Induk Brebes, pada kecamatan Wanasari diambil data penelitian di Simpang 3 Pebatan, pada kecamatan Bulakamba diambil data penelitian Simpang 3 Pasar Bawang Klampok, dan pada kecamatan Losari diambil data penelitian di simpang 4 Losari.

Metode pengambilan data volume simpang jalan pantura Kabupaten Brebes dilaksanakan pada 5 jam pada jam puncak pagi dan 3 jam pada jam puncak sore. Pada jam puncak pagi dilaksanakan pada jam 08.00 - 13.00 WIB sedangkan pada jam puncak sore dilaksanakan pada jam $15.30-18.30$ WIB.

Tabel 5. Data Volume Simpang Tertinggi Jalan Pantura Kabupaten Brebes

\begin{tabular}{lcc}
\hline $\begin{array}{l}\text { Lokasi Pengambilan } \\
\text { Data Volume Simpang }\end{array}$ & \multicolumn{2}{c}{$\begin{array}{c}\text { Volume Lalu Lintas } \\
\text { (smp/jam) }\end{array}$} \\
\cline { 2 - 3 } & $\begin{array}{c}\text { Jam } \\
\text { Puncak } \\
\text { Pagi }\end{array}$ & $\begin{array}{c}\text { Jam } \\
\text { Puncak } \\
\text { Sore }\end{array}$ \\
\hline $\begin{array}{l}\text { Pasar Induk Brebes } \\
\text { (Brebes) }\end{array}$ & 2803.20 & 2834.20 \\
\hline $\begin{array}{l}\text { Simpang 3 Pebatan } \\
\text { (Wanasari) }\end{array}$ & 2701.20 & 2449.90 \\
\hline $\begin{array}{l}\text { Simpang 2 Pasar } \\
\text { Bawang Klampok } \\
\text { (Bulakamba) }\end{array}$ & 2060.80 & 2144.40 \\
\hline $\begin{array}{l}\text { Simpang 4 Losari } \\
\text { (Losari) }\end{array}$ & 2486.50 & 2569.00 \\
\hline
\end{tabular}

\section{Analisis Kapasitas}

(1) Analisis Kapasitas Ruas

Kapasitas pada masing-masing ruas jalan akan berbeda-beda sesuai dengan dimensi jalan yang ada, aktifitas kegiatan jalan yang berlangsung dan lain sebagainya. Dari penelitian yang dilakukan, hasil kapasitas yang tersedia pada tiap-tiap ruas yang diambil yaitu pada ruas Kecamatan Brebes, Kecamatan Wanasari, Kecamatan Bulakamba dan Kecamatan Losari.

(2) Analisis Kapasitas Simpang

Kapasitas pada masing-masing simpang akan berbeda-beda sesuai dengan dimensi simpang yang ada, aktivitas kegiatan jalan yang berlangsung dan lain sebagainya.

\section{Analisis Derajat Kejenuhan}

Derajat kejenuhan merupakan rasio volume per kapasitas, yakni rasio arus lalulintas Q (smp/jam) terhadap kapasitas C (smp/jam) pada bagian jalan tertentu.

(1) Analisis Derajat Kejenuhan pada Ruas 
Perhitungan rasio volume per kapasitas pada penelitian ini yaitu dengan memisalkan volume kendaraan yang ada melintas pada masing-masing kapasitas pada ruas untuk setiap volume dan kapasitas pada masingmasing kecamatan.

Tabel 6. Derajat Kejenuhan pada Ruas Jalan Pantura Kabupaten Brebes

\begin{tabular}{|c|c|c|c|c|c|c|c|c|c|c|}
\hline No & Ruas & Kecamatan & $\begin{array}{l}\text { Perkotaan/ } \\
\text { Luar Kota }\end{array}$ & C & $\begin{array}{c}\text { Volume } \\
\text { Pagi } \\
\text { (smp/jam) }\end{array}$ & $\begin{array}{l}\text { VCR } \\
\text { (Pagi) }\end{array}$ & $\begin{array}{c}\text { Kecepa } \\
\text { tan } \\
\text { (Pagi) }\end{array}$ & $\begin{array}{c}\text { Volume } \\
\text { Sore } \\
\text { (smp/jam) }\end{array}$ & $\begin{array}{l}\text { VCR } \\
\text { (Sore) }\end{array}$ & $\begin{array}{c}\text { Kecepa } \\
\text { tan } \\
\text { (Sore) }\end{array}$ \\
\hline 1 & Ruas 1 & \multirow{9}{*}{ Brebes } & Perkotaan & 5829.12 & \multirow{9}{*}{4504} & 0.77 & \multirow{9}{*}{38.7} & \multirow{9}{*}{4106} & 0.70 & \multirow{9}{*}{42.36} \\
\hline 2 & Ruas 2 & & Perkotaan & 5829.12 & & 0.77 & & & 0.70 & \\
\hline 3 & Ruas 3 & & Perkotaan & 6314.88 & & 0.71 & & & 0.65 & \\
\hline 4 & Ruas 4 & & Perkotaan & 6700.32 & & 0.67 & & & 0.61 & \\
\hline 5 & Ruas 5 & & Perkotaan & 6557.76 & & 0.69 & & & 0.63 & \\
\hline 6 & Ruas 6 & & Perkotaan & 6314.88 & & 0.71 & & & 0.65 & \\
\hline 7 & Ruas 7 & & Perkotaan & 6314.88 & & 0.71 & & & 0.65 & \\
\hline 8 & Ruas 8 & & Perkotaan & 7270.56 & & 0.62 & & & 0.56 & \\
\hline 9 & Ruas 9 & & Perkotaan & 6557.76 & & 0.69 & & & 0.63 & \\
\hline 10 & Ruas 10 & \multirow{2}{*}{ Wanasari } & Luar Kota & 6992 & \multirow{2}{*}{5034} & 0.72 & \multirow{2}{*}{43.87} & \multirow{2}{*}{4886} & 0.70 & \multirow{2}{*}{46.26} \\
\hline 11 & Ruas 11 & & Luar Kota & 6992 & & 0.72 & & & 0.70 & \\
\hline 12 & Ruas 12 & \multirow{2}{*}{ Bulakamba } & Luar Kota & 7068 & \multirow{2}{*}{4364} & 0.62 & \multirow{2}{*}{54.87} & \multirow{2}{*}{4002} & 0.57 & \multirow{2}{*}{56.88} \\
\hline 13 & Ruas 13 & & Luar Kota & 7514.88 & & 0.58 & & & 0.53 & \\
\hline 14 & Ruas 16 & Losari & Luar Kota & 7077.12 & 2743 & 0.39 & 58.06 & 2646 & 0.37 & 61.38 \\
\hline
\end{tabular}

(2) Analisis Derajat Kejenuhan pada Simpang Persimpangan jalan adalah simpul pada jaringan jalan dimana ruas jalan bertemu dan lintasan arus kendaraan berpotongan. Lalu lintas pada masing-masing kaki persimpangan menggunakan ruang jalan pada persimpangan secara bersama-sama dengan lalu lintas lainnya. Persimpangan merupakan tempat sumber konflik lalu lintas yang rawan terhadap kecelakaan karena terjadi konflik antara kendaraan dengan kendaraan lainnya ataupun antara kendaraan dengan pejalan kaki. Derajat kejenuhan ( DS ) didefenisikan sebagai rasio arus lalu lintas terhadap kapasitas, yang digunakan sebagai faktor utama dalam penentuan tingkat kinerja simpang dan segmen jalan. Nilai DS menunjukkan apakah segmen jalan tersebut mempunyai masalah kapasitas atau tidak. Derajat Kejenuhan pada masing-masing simpang dapat dilihat pada tabel berikut ini.
Tabel 7. Derajat Kejenuhan pada Simpang Jalan Pantura Kabupaten Brebes

\begin{tabular}{cccc}
\hline \multicolumn{4}{c}{ Jam Puncak Sore } \\
\hline Arus & Kapasitas & $\begin{array}{c}\text { Derajat } \\
\text { Kejenuhan }\end{array}$ & $\begin{array}{c}\text { Kecepatan } \\
(\mathrm{v})\end{array}$ \\
\hline 1489 & 1659 & 0.88 & 42.26 \\
\hline 1180 & 2103 & 0.56 & 46.26 \\
\hline 892 & 1590 & 0.56 & 56.88 \\
\hline 1050 & 1158 & 0.91 & 61.38 \\
\hline
\end{tabular}

\section{Analisis Kinerja Jalan ( LoS)}

Analisis kinerja jalan bermaksud untuk mengetahui tingkat pelayanan jalan/LoS (level of service). Tingkat pelayanan jalan adalah ukuran yang menyatakan kualitas pelayanan yang disediakan oleh suatu jalan dalam kondisi tertentu. Perhitungan LoS ini akan menjadi justifikasi adanya permasalahan kemacetan lalu lintas. Aspek-aspek yang mempengaruhi tingkat pelayanan jalan yaitu kecepatan kendaraan, volume lalu-lintas, kapasitas jalan dan hambatan samping. Pada ruas yang berada di kecamatan Brebes mempunyai Nilai LoS E, kecamatan Wanasari mempunyai Nilai LoS E, Bulakamba mempunyai nilai LoS D, dan Kecamatan Losari mempunyai nilai LoS C. Sedangkan 
pada Simpang Pasar Induk Brebes (Kecamatan Brebes) mempunyai nilai LoS E, Simpang 3 Pebatan (Kecamatan Wanasari) mempunyai nilai LoS C, Simpang 3 Pasar Bawang Klampok Bulakamba (Kecamatan Bulakamba) mempunyai nilai LoS C, dan Simpang 4 Losari (Kecamatan Losari) mempunyai nilai LoS D.

\section{Prediksi Pertumbuhan Lalu-Lintas Pada Tahun 2017-2021 Jalan Pantura Kabupaten Brebes}

Perhitungan prediksipertumbuhan lalu-lintas jalan pantura kabupaten Brebes pada 5 tahun ke depan bertujuan untuk mengetahui perkiraan volume lalu lintas di masa yang akan datang selama 5 tahun ke depan. Berdasarkan hasil penelitian yang telah dilaksanakan pada ruas dan simpang jalan pantura Kabupaten Brebes di peroleh data rasio volume per kapasitas yang berbeda-beda di setiap kecamatan Berdasarkan hasil evaluasi pada Ruas dan Simpang Jalan Pantura Kabupaten Brebes tersebut, maka pada ruas dan simpang yang mempunyai kategori Kondisi III dan IV perlu diadakan redesign jalan untuk mengurangii tingkat kemacetan pada jalan tersebut. Kondisi III yaitu dimana nilai VCR 0.90 - 1.00, sedangkan kondisi IV yaitu dimana nila VCR $>1.00$. Untuk ruas maka harus diperbaiki secara keseluruhan, sedangkan untuk simpang hanya dilakukan pada kecamatan Brebes dan kecamatan Losari saja.

\section{Solusi Permasalahan pada Ruas Jalan Pantura Kabupaten Brebes}

Penambahan Lajur Jalan

Solusi menghilangkan hambatan samping dan pelebaran jalan dari hasil analisa diatas kurang efektif maka perlu diadakan perbaikan lain yaitu dengan cara menambah lajur jalan pada kedua arah. Penambahan lajur tentu saja dengan melalukan pembebasan lahan di kanan dan kiri jalan yang akan dibenahi. Lebar penambahan lajur untuk kedua arah yaitu badan jalan sebesar 3 meter dan bahu jalan pada daerah perkotaan selebar 1,5 meter serta bahu jalan pada daerah luar kota sebesar 1 meter. Dimensi perbaikan jalan tersebut besarnya telah diperhitungkan kapasitasnya dalam kebutuhan kendaraan yang di prediksi meningkat pada tahun 2021.

Solusi Permasalahan pada Simpang Jalan Pantura Kabupaten Brebes Menambah Lebar Jalan Pendekat pada Simpang
Pada kondisi ini dilakukan penambahan lebar jalur pendekat pada simpang, yang bertujuan untuk menambah kapasitas kendaraan sehingga derajat kejenuhan pada simpang ini bisa berkurang dan menjadi lebih stabil. Pelebaran jalan juga berpengaruh pada waktu siklus dan waktu hijau yang dapat mengurangi derajat kejenuhan menjadi lebih kecil.

\section{KESIMPULAN}

(1) Dari hasil analisis kapasitas ruas jalan pantura Kabupaten Brebes maka diperoleh nilai volume lalu lintas terbesar pada jam puncak pagi dan pada jam puncak sore berada pada kecamatan Wanasari, yaitu 5034 smp/jam pada jam puncak pagi, sedangkan pada jam puncak sore sebesar $4886 \mathrm{smp} / \mathrm{jam}$.

(2) Dari hasil analisis kecepatan kendaraan maka diperoleh nilai kecepatan terbesar pada jam puncak pagi dan jam puncak sore berada pada kecamatan Losari yaitu $61.73 \mathrm{~km} / \mathrm{jam}$ ( jam puncak pagi ) dan $65.11 \mathrm{~km} / \mathrm{jam}$ ( jam puncak sore ).

(3) Berdasarkan hasil analisis kapasitas simpang jalan pantura Kabupaten Brebes diperoleh volume maksimal pada jam puncak pagi dan jam puncak sore berada di kecamatan Brebes, yaitu 2803,20 smp/jam ( jam puncak pagi ), dan 2834,20 smp/jam(jam puncak sore).

(4) Berdasarkan hasil penelitian yang telah dilaksanakan pada ruas dan simpang jalan pantura Kabupaten Brebes diperoleh data rasio volume per kapasitas yang berbeda-beda di setiap kecamatan. Kondisi I: VCR < 0.85; Kondisi II : VCR 0.85 - 0.90; Kondisi III : VCR 0.90 - 1.00; Kondisi IV : VCR > 1.00. Berdasarkan hasil evaluasi pada Ruas dan Simpang Jalan Pantura Kabupaten Brebes tersebut, maka pada ruas dan simpang yang mempunyai kategori Kondisi III dan IV perlu diadakan redesign jalan untuk mengurangi tingkat kemacetan pada jalan tersebut. Kondisi III yaitu dimana nilai VCR 0.90 - 1.00, sedangkan kondisi IV yaitu dimana nila VCR $>1.00$. Untuk ruas maka harus diperbaiki secara keseluruhan, sedangkan untuk simpang hanya dilakukan pada kecamatan Brebes dan kecamatan Losari saja.

(5) Semakin besar nilai rasio volume per kapasitas, maka semakin besar pula tingkat kemacetan yang terjadi. 
Untuk mengurangi tingkat kemacetan lalu lintas yang ada di Jalan Pantura Kabupaten Brebes maka perlu diadakan penanganan sebagai berikut :

(1) Penanganan pada Ruas Jalan Pantura Kabupaten Brebes dapat dilakukan solusi pelebaran jalan. Pada perbaikan ini melihat perubahan besarnya kapasitas jalan yang tersedia apabila lebar jalan diperbesar sehingga dapat memenuhi peningkatan kendaraan yang di prediksi terjadi pada tahun 2021.

(2) Penambahan Lajur Jalan

Penambahan lajur tentu saja dengan melakukan pembebasan lahan di kanan dan kiri jalan yang akan dibenahi. Lebar penambahan lajur untuk kedua arah yaitu badan jalan sebesar 3 meter dan bahu jalan pada daerah perkotaan selebar 1,5 meter serta bahu jalan pada daerah luar kota sebesar 1 meter.

\section{DAFTAR PUSTAKA}

Ali Murtopo. 2013. Analisis Hubungan Rasio Volume per Kapasitas dan Angka Kecelakaan Lalu-lintas di Jalan Pantura Kabupaten Brebes. (Skripsi). Semarang. Universitas Negeri Semarang

Direktorat Jendral Bina Marga. 1997. Manual Kapasitas Jalan Indonesia. Jakarta : Bina Marga

Kementrian Pekerjaan Umum. 2014. Pedoman Bahan Konstruksi Bangunan dan Rekayasa Sipil ( rancangan 3 ) Kapasitas Simpang Tahun 2014. Jakarta. Menteri Perhubungan Republik Indonesia.

2015. Peraturan Menteri Perhubungan Republik Indonesia No. PM 96 Tahun 2015 tentang Pedoman Pelaksanaan Kegiatan Manajemen dan Rekayasa Lalu-lintas. Jakarta. Menteri Perhubungan Republik Indonesia.

2006. Peraturan Menteri Perhubungan Nomor KM 14 Tahun 2006 tentang Manajemen dan Rekayasa Lalu-lintas di Jalan. Jakarta. Wikipedia. 2015. Kapasitas Jalan.

http://id.wikipedia.org/wiki/Kapasitas J alan. Diunduh pada 10/10/2015 pukul 19.35

Nurul Fadhilah. 2013. Pengaruh Volume Kendaraan dengan Tingkat Kerusakan Jalan pada Perkerasan Rigid di Kota Semarang. (Skripsi). Semarang. Universitas Negeri Semarang.
Octavianus E.T Dendo. 2013. Kajian Tingkat Pelayanan Jalan Bunderan PU Kota Kupang. (Jurnal). Kupang. Teknik Sipil Vol.III, No.1, April 2014.

Republik Indonesia. 2004. Undang-undang No. 38 Tahun 2004 tentang Jalan. Jakarta.

Republik Indonesia. 1985. Peraturan Pemerintah Republik Indonesia No. 26 Tahun 1985 tentang Jalan. Jakarta.

Sumadi. 2006. Kemacetan Lalu Lintas pada Ruas Jalan Veteran Kecamatan Brebes. (Tesis). Semarang. Universitas Diponegoro. 